\title{
Race, culture and psychotherapy
}

\author{
Penelope Campling, Senior Registrar in Psychotherapy, Humberstone Grange Clinic, \\ Leicester LE5 0TA
}

I have recently taken up a post as Senior Registrar in Psychotherapy in Leicester where about $20 \%$ of the citizens are Asian or Afro-Caribbean. For the rest of this article I shall use the term 'black' as synonymous with Asian and Afro-Caribbean. While realising this may offend some readers, I use it in a political sense and know that many prefer it to the equally inaccurate use of the term 'ethnic minority'. Before being promoted, I was on the general psychiatry registrar rotation in the same city and not surprisingly had a large number of black patients. Now I have none; there are very few referred to the Department, and I gather this is typical of psychotherapy units across the country. I want to consider why this is so, and what, if anything, should be done about it.

Over the last decade, an important focus of multicultural research has been the attitudes and practice of professionals when working with black patients. The excess of compulsory admissions transfers to locked wards, and the over use of Section 136 are all examples where professional assessment of dangerousness has presumably been influenced in some way by the colour of the patient's skin. There is also some evidence that black patients get higher drug dosages and are more frequently given physical treatment like ECT, independent of their diagnosis. The rejection of black patients as potential candidates for psychotherapy has been frequently noted but has received relatively little publicity or concern. However, if we are to aspire towards a nonracist service, the whole spectrum of psychiatric practice needs to be examined, and the imbalance redressed.

Why then are black patients so rarely referred on for psychotherapy? Linguistic difficulties are an obvious problem and it is indeed hard to imagine practising psychotherapy with the help of an interpreter! However, certainly in Leicester the majority of black patients speak adequate English and many in fact were born in this country.

'Language' is not a straightforward matter and encompasses a wide diversity of cultural behaviours and communications that are not translatable or understandable when taken out of context. Thus, the problem of inter-cultural diagnosis continues to provide psychiatrists with food for debate and the possible over-diagnosis of schizophrenia has been a focus of research and publicity. It has also been noted that black patients have a tendency to present with somatic symptoms, rather than talk about emotional problems. Using data from the International Pilot Study of Schizophrenia, Leff related linguistic factors to culturally determined ways of expressing emotion and concluded that there has been a progressive differentiation of the vocabulary of emotion as a "historic process" so that "in many cultures today emotional distress is still communicated through a rich variety of somatic symptoms". The "shift in focus from the bodily expression of distress to its communication through language, with a consequent progressive differentiation of the vocabulary of emotion" is seen as an "evolutionary process" (Leff, 1977). From here, it is a small jump to say that black patients are not psychologically minded or verbally sophisticated enough to make use of "the talking treatment". This is a gross simplification and misunderstanding of what actually takes place in psychotherapy, but in this article I want to focus on the assumption made about black patients and black races.

Our own thinking on somatic symptoms is influenced by the fact that 'modern' psychiatry, including psychoanalysis, has its roots in the Cartesian view of a person as a dualism of mind and body, which has dominated Western philosophy and scientific thinking. This is different from the Eastern tradition, where the focus is wholeness and balance. Thus it may be that the significance of somatic symptoms is different in patients from other cultures and should not necessarily be regarded with disapprobation as a particularly impervious form of defence mechanism, or lead to the assumption that they are not accessable to so-called "verbal therapies". Even if theoretical notions of individuation are to a certain extent 'Western', we are not concerned in Britain with providing psychotherapy for some hypothetical Third World community. Littlewood (1988) reminds us, "we are talking of ourselves, a proportion of citizens in Britain now, a disadvantaged group certainly, but emphatically not one which has some sort of exotic system of psychological and personal development". In fact, there are somatic presentations in psychiatry such as anorexia nervosa which receive a lot of psychological therapy.

It is sometimes feared that professional intervention may have the effect of deskilling a particular group of people, that by offering psychotherapy, we may undermine the grassroot network inherent in a community. This is a particular concern with Asian 
patients who are usually assumed to belong to closeknit extended families. Thus these patients may not be offered therapy for fear of weakening 'sacrosanct' family ties. While it is important to be sensitive to these sort of issues, they are no excuse for doing nothing; generalisations must be recognised as such and heterogeneity within cultures appreciated.

Some psychotherapists worry that their lack of cultural sensitivity may cause them to do more harm than good. In America, where there has been more research on this subject, ethnic minorities were not only under-represented, but had significantly higher drop-out rates, particularly early in treatment. And yet, as a profession, we are well used to grappling with situations where our value judgements conflict with those of our patients; we are used to dispensing with 'categories' in order to concentrate on the individual, and many of us are used to using theoretical models flexibly and pragmatically, rather than imposing them on our patients. In America, the almost exclusive emphasis on 'cultural responsiveness' in the practice of intercultural psychotherapy is being questioned; and it is recognised that cultural knowledge and techniques generated by this knowledge are frequently applied in inappropriate ways. There are many examples of professionals acting on insufficient knowledge or overgeneralising what they have learnt about culturally dissimilar groups (Sue \& Zane, 1987). In this country, Fernando writes "Psychiatry conceals, defends and maintains racism by culturizing it" and makes many appeals in his book to disentangle race and culture (Fernando, 1988).

Of concern is the issue of power in a therapeutic relationship between black client and white therapist. This is a country where black people suffer discrimination at the hands of professionals in education, housing, social services, law enforcing agencies, penal establishments, as well as the mental health field; where reports of atrocities in South Africa reach us everyday and the Government and our own professional governing bodies refuse to enforce sanctions; where humiliation and fear at the hands of overt racists is part of black citizens' everyday experience. It is a nonsense to aspire to a 'colourblind' approach. The essential assymetry which characterises the therapeutic relationship, lends itself to abuse and misunderstanding, if power relations and racism in society are not recognised and faced as live issues in therapy. Some of Freud's case histories of women patients are good examples of this type of abuse, but an alternative scenario is for the therapist to be aware of these issues and not to allow them to paralyse or inhibit therapeutic interventions. We cannot open the doors to black patients and hope to exclude the pain and hurt of racism from our therapeutic encounters. It is this we resist, and I believe worries about 'cultural sensitivity' are in part a rationalisation.

I have started to write as if psychotherapists are responsible for the fact that blacks are underrepresented among their patients. Certainly in Leicester, it is the lack of referrals that is significant, not the number we turn away. However, I cannot escape the fact that I am working in a virtually white institution in the heart of a multicultural city. According to the sociologist Wellman, racism is not just about attitudes, but about "institutionally generated inequality". "Prejudiced people are not the only racists" he writes, as he argues that racism then arises from thinking that is rational and correct within the culture (Wellman, 1977).

Unfortunately, psychotherapy is a Cinderella speciality. Here in Leicester we are desperately short of staff, with a patient waiting list of 12 months. We are certainly not in the position to go out canvassing for patients, and would find it hard to deal with any increase in referrals. Even if we had the resources or decided to make the issue a high priority, it is not clear how we should change the situation. If they had a real choice, would black patients choose to come to a white institution? How do we lessen the credibility gap? Should we positively discriminate for black therapists? Is there potential for using Section II money? Should we leave well alone and wait for black staff or patient groups to approach us? Should we campaign for special services such as 'Nafsiyat' in London? (Acharyya et al, 1989).

My own view is that 'special services', use of Section II money, and a focus on 'ethnic matching', while they might be useful short term strategies, should not obscure the need for NHS psychotherapy departments and individual psychotherapists to provide a sensitive service for black patients. Analysis of our benign indifference may be a good starting point.

\section{References}

ACHARYya, S., MOORHOUSE, S., KAREem, J. \& LitTlewOOd, R. (1989) Nafsiyat: a psychotherapy centre for ethnic minorities. Psychiatric Bulletin of the Royal College of Psychiatrists, 13, 358-360.

FERnANDO, S. (1988) Race and Culture in Psychiatry. London and Sydney: Croom Helm.

LEFF, J. (1977) The cross-cultural study of emotions. Culture, Medicine and Psychiatry, 1, 317-350.

LITTLEWOOD, R. (1988) Towards an inter-cultural therapy: Some preliminary observations. Journal of Social Work Practice, 3, 8-19.

SUE, S. \& ZANE, N. (1987) The role of culture techniques in psychotherapy. American Psychologist, 42, 37-45.

Wellman, D. (1977) Portraits of White Racism. Cambridge: Cambridge University Press.

A full list of references is available on request to the author. 